\title{
A propagação da crença escolar ou o "contágio da convicção": Os ritos de instituição no romance $\boldsymbol{O}$ Ateneu
}

\author{
Tiago Ribeiro Santos \& Rita de Cássia Marchi \\ Universidade Regional de Blumenau (FURB), Brasil
}

\section{Resumo}

Este artigo, na interface da sociologia da educação com a história da educação, apresenta uma análise dos ritos de instituição descritos no romance $O$ Ateneu, de autoria do escritor brasileiro Raul Pompeia, publicado originalmente em 1888. O romance retrata o cotidiano escolar de um colégio de elite da época. Os ritos de instituição no colégio Ateneu atuam no sentido de produzir - reproduzindo - a crença na vida escolar, estabelecendo diferenças entre os indivíduos a que são direcionados. Nesse sentido, os ritos escolares atuam no convencimento dos agentes à adesão e participação nas diversas atividades do colégio, orquestrando de forma coletiva os diversos interesses, disposições e modos de conduta.

\section{Palavras-chave}

Ritos de instituição; Vida escolar; Romance

\section{Introdução}

Este estudo, na interface da sociologia da educação com a história da educação, apresenta uma análise sobre os ritos de instituição descritos no romance $O$ Ateneu, de autoria do escritor brasileiro Raul Pompeia, publicado originalmente em 1888. Esse romance, considerado uma das obras literárias brasileiras de maior destaque do século XIX, narra a experiência escolar de Sérgio (menino de 11 anos) como aluno interno em colégio da elite brasileira da época. 
Representado no romance como uma escola, o Ateneu é lugar de produção e preservação de ritos, crenças e técnicas produtoras de um ethos específico. Assim, o romance de Pompeia, ao 'retratar' (tal como o realismo funcionalista o faria) a vida em um colégio - que muitos supõem ter sido por ele mesmo frequentado ${ }^{1}$-, permite compreender o que Bourdieu (1996) enuncia em sua obra As Regras da Arte como sendo o trabalho de "dessacralização" da obra literária eleita como objeto de estudo das Ciências Sociais: a literatura pode, por vezes, dizer mais sobre o mundo social do que muitos estudos com pretensão científica. Entendemos que, para Bourdieu, isso deriva da forma como a literatura constrói a 'realidade' que enuncia. Deste modo, estamos aqui objetivando uma forma de ilusão que, em verdade, nada tem de ilusória:

Objetivar a ilusão romanesca e, sobretudo, a relação com o mundo dito real que ela supõe, é lembrar que a realidade com a qual comparamos todas as ficções não é mais que o referente reconhecido de uma ilusão (quase) universalmente partilhada (Bourdieu, 1996, p. 50).

Esse autor se refere às possibilidades que a ficção (enquanto narrativa) oferece relativamente ao conhecimento de uma 'certa realidade' (no caso d'O Ateneu, a 'realidade' ou o 'modo de vida' escolar). Ou seja, a literatura, seja ela ficção no sentido estrito do termo, seja como 'realidade tangível' (uma autobiografia que fosse, por exemplo, a de Raul Pompeia), sempre nos dá algo a conhecer.

Assim, a análise do romance "deve reduzir a narração de uma aventura ao protocolo de uma espécie de montagem experimental" (Bourdieu, 1996, p. 44). Esta montagem decorre do pressuposto que a obra literária, relativamente autônoma, se oferece ao leitor como objeto a ser decifrado a partir daquilo que ela mesma diz, "mas ela o diz apenas de um modo tal que não o diz realmente" porque a formalização literária (conduzida pelo escritor) opera "como um eufemismo generalizado" (Bourdieu, 1996, p. 44). Buscamos, portanto, a fundamentação metodológica deste artigo sobre $O$ Ateneu na obra As Regras da Arte, de P. Bourdieu, onde esse autor considera que $\mathrm{a}(\mathrm{s})$ forma(s) do discurso literário condiciona $(\mathrm{m})$ a leitura interna do romance, nos revelando um modo de apreciação que é o do espaço social nele representado. Assim, no caso deste estudo, no romance de Pompeia, o "colégio Ateneu" (educandário da elite brasileira no século XIX) pode ser 
compreendido como um microcosmos daquela sociedade (a do Segundo Império).

É apenas nesse restrito sentido que afirmamos transitar, nesse estudo, entre os campos disciplinares da Sociologia e o da História (conhecimentos socialmente reconhecidos como científicos), tendo por veículo a Literatura. Assim, se aqui reivindicamos uma interface entre a sociologia e a história da educação, o fazemos a partir da "inevitável tensão" que a História, ao interrogar a si mesma, de acordo com Bourdieu e Chartier (2011), estabelece entre a intenção de conhecimento da disciplina e a forma necessariamente narrativa de sua escrita. Isto é, partimos da via aberta pelo distanciamento que, a partir da década de 80 , segundo esses autores, os historiadores começaram a tomar em relação aos princípios de análise próprios da tradição dessa disciplina: aqueles mais especialmente preocupados (ou com preferência) pelas fontes maciças, o tratamento quantitativo, a constituição de séries.

Assim, consideramos que o romance tem em comum com as microhistórias a abordagem que tem por motivo mais as representações coletivas do que as classificações objetivas, mais as apropriações singulares e as estratégias conscientes do que as determinações desconhecidas (Bourdieu \& Chartier, 2011). Por isso, esse artigo é também um convite (ou incentivo) a refletir sobre a "capacidade cognitiva da ficção" (Bourdieu \& Chartier, 2011, p. 11).

Portanto, se do ponto de vista sociológico procuramos, a partir da leitura interna da obra, "construir sistemas de relações inteligíveis capazes de explicar os dados sensíveis" do romance (Bourdieu, 1996, p. 14), do ponto de vista da história da educação, esse artigo procura contribuir com "o uso desse tipo de fonte para se pensar a história da educação" tal como sugerido por Gondra (1999, p. 33), em estudo sobre O Ateneu.

\section{Os ritos de instituição}

Neste artigo considera-se que os ritos de instituição que atuam no Ateneu fazem parte de um sistema orientado para instituir e preservar, reproduzindo, o arbitrário cultural vivenciado no colégio. Por conseguinte, nosso objetivo é destacar as condições simbólicas que permitiam que os ritos de instituição atuassem no colégio de modo a assegurar sua ordem interna². 
Os ritos escolares (solenidades, eventos festivos, prêmios, louvores, condecorações, etc.) podem ser compreendidos, de acordo com Saviani (2008), como "mecanismos de incentivo ao trabalho escolar" (p. 52) e sinalizam, na história da educação, uma mudança no modus operandi (a passagem do modus italicus para o modus parisienses) do sistema de ensino ocidental a partir do século XVI. Neste artigo apreendemos esses "mecanismos de incentivo", ou esses ritos escolares, do ponto de vista sociológico, como "ritos de instituição".

Os "ritos de instituição" são um conceito desenvolvido por Bourdieu (1982) a partir do conceito clássico em antropologia social de "ritos de passagem". Nesse novo conceito, Bourdieu pretende conferir aos ritos (mais especificamente escolares) características além daquelas já atribuídas aos ritos de passagem, notadamente pelos antropólogos VanGennep (1978) e Turner (1974). Para Bourdieu (1982), "todo o rito tende a consagrar ou a legitimar, ou seja, a fazer desconhecer enquanto arbitrário e reconhecer enquanto legítimo, natural, um limite arbitrário" (p. 58). O "limite" a que o autor se refere é a linha simbólica que marca a passagem entre o antes e o depois. Isto é, a linha (demarcada pelo rito) que sinaliza uma mudança de estado, que sinaliza a passagem de uma determinada condição a outra. Assim, os ritos de passagem são também compreendidos como "ritos de iniciação", pois marcam essa transição - metaforicamente compreendida como "morte" e "renascimento" simbólicos - de um status social a outro.

De acordo com autores da antropologia social, o ritual é um sistema de comunicação simbólica que serve para "organizar" aspectos da vida social Ihes emprestando formas convencionais e estilizadas. Sabe-se, a partir disto, que uma característica comum a rituais de todo tipo é a repetição, que tem a função de conceder familiaridade e, portanto, segurança às pessoas (Rodolpho, 2004). Esse sentimento de segurança (ontológica) nos acomete porque, a partir da familiaridade que temos com determinados rituais e seus desdobramentos ou sequências, "sabemos o que vai acontecer, celebramos nossa solidariedade, partilhamos sentimentos, enfim, temos uma sensação de coesão social" (Rodolpho, 2004, p. 139). Trata-se, portanto, também do sentimento de pertencimento a determinado grupo, instituição, nação, etc. Nesse sentido é que os rituais podem ser compreendidos como "manifestos contra a indeterminação"; portanto, como atos simbólicos que visam expurgar 
as incertezas (e inseguranças) que constituem, por outro lado, nossa (regrada) vida social. Podendo os rituais ser profanos ou de caráter religioso, têm, de todo modo, a capacidade de tornar visível o invisível: no caso dos rituais escolares, eles tornam visíveis, demarcam, reforçam, tornam patentes as relações sociais presentes no universo escolar fortemente estruturado pela hierarquia de posições e pela demarcação de diferenças quanto a condutas e desempenhos prescritos/proscritos naquele espaço ${ }^{3}$.

De acordo com VanGennep (1978), as cerimônias são etapas daquilo que se deseja marcar ou revelar socialmente, uma espécie de "moldura" que se deseja aplicar a determinada realidade (seja ela qual for). Nesse sentido, o rito da cerimônia circunscreve e torna consciente (visível), enfim, o fato social. Assim, Bourdieu pretendeu enfatizar a "função social" dos ritos de passagem e do significado social da linha divisória (separação) que o ritual institui entre os que foram submetidos (ou ainda serão) a essa ação simbólica e aqueles que não a sofrerão (instituindo, assim, uma diferença durável entre agentes) (Bourdieu, 1982). É por causa dessa demarcação social que o autor renomeia os ritos de passagem como "ritos de consagração", "ritos de legitimação" ou, mais precisamente, "ritos de instituição" (rites d'institution), conferindo a essa última palavra seu sentido 'ativo', isto é, o de instituir, de dar forma, de 'fazer ver' (e, portanto, de fazer crer).

Os ritos escolares são representados n'O Ateneu como festas, exames, solenidades, condecorações, eventos esportivos e literários e outras atividades que instituem a rotina escolar. Dentre esses, os ritos analisados nesse estudo são: os exames de avaliação aos quais os alunos são submetidos; a posterior divulgação das notas por meio do "livro das notas"; e as solenidades de final de ano (notadamente a "festa da ginástica"), que reúnem apresentações artísticas que tornam visíveis os resultados obtidos no decorrer do ano letivo e que contam também com a participação da comunidade externa, isto é, dos pais dos alunos, de políticos proeminentes, de professores e nobres da sociedade da época que o romance descreve. 


\section{A festa da ginástica e "as galas" que fazem "sorrir a paisagem"}

No âmbito da história da educação, Gondra (2004) assinala que, no século XIX, 'educar' e 'civilizar' tinham o mesmo sentido e que a pedagogia, no projeto utópico de uma "educação integral", se constituía, no marco positivista da época, como "educação do corpo", "disciplina da inteligência" e "ginástica da vontade". Assim, o evento ginástico realizado no colégio Ateneu, se produzido pela disciplina da "educação física", pode também ser analisado como elemento altamente performático (no sentido de um jogo estético) que, se tem por pressuposto o consenso, ao mesmo tempo (re)cria essa fundamental condição para que ocorra. Isso porque, com regras (muito) bem definidas, nesse jogo o que se disputa são os bens simbólicos advindos da exibição (exitosa, triunfante) do resultado de corpos trabalhados pela "ginástica da vontade" (Gondra, 2004). Nas palavras de Sérgio - narrador do romance -, os eventos ginásticos do Ateneu (ou o ritual da festa da ginástica), apresentavam o "triunfo espetaculoso da saúde, da força, da mocidade" que habitava aquele internato. Isto é, cabia aos ritos a função de consagrar a saúde (moral e física) que necessariamente havia de exalar dos corpos aptos àquela exibição pública.

A transformação do espaço escolar faz parte do caráter extraordinário que se confere aos ritos da "festa da ginástica" n'O Ateneu. Este caráter extraordinário só pode ser percebido em relação ao caráter banal ou ordinário em que se apresentam outras atividades no cotidiano escolar e que o definem enquanto tal: o regime dos horários, as disciplinas, o mobiliário, etc. Mas as galas - e sua forma extraordinária - não podem ser completamente abstraídas da rotina do colégio, pois nela estão também previstas. Portanto, se os ritos se destacam do cotidiano escolar, isto se deve porque atuam como forças que tornam extraordinário o caráter ordinário da vida escolar, transformando-a momentaneamente:

Transformara-se em anfiteatro uma das grandes salas da frente do edifício, exatamente a que servia de capela; paredes estucadas de suntuosos relevos, e o teto aprofundado em largo medalhão, de magistral pintura (...). Desarmado o oratório, construíram-se bancadas circulares, que encobriam o luxo das paredes. Os alunos ocupavam a arquibancada. Como a maior concorrência preferia sempre a exibição dos exercícios ginásticos, (...), o público, pais e correspondentes em geral, porém mais numeroso do que se esperava, tinha que transbordar da sala da festa para a imediata (Pompeia, 1993, p. 25). 
A transformação da arquitetura do espaço escolar por ocasião dos ritos implica na valorização desses. Ora, dispensar tempo, energia e trabalho a favor das atividades rituais pressupõe a sua legitimação no espaço escolar. Deste modo, os integrantes do colégio, sejam professores, diretor, alunos, bedéis, etc., mobilizam-se em torno dessas atividades fazendo delas produto de um trabalho comum e solidário, isto é, produto de uma emoção ou sentimento partilhado. A modificação do espaço escolar, consequentemente, modifica também a impressão que dele se tem. Assim, a inicial aparência festiva da escola descrita por Sérgio é posteriormente transformada pela melancolia que o atravessava como aluno interno àquele espaço: o rito tinha o poder de colocar em suspenso o caráter tristonho da escola porque provocava a transformação do que aquele espaço significava:

As eminências de sombria pedra e a vegetação selvática debruçavam sobre o edifício um crepúsculo de melancolia, resistente ao próprio sol a pino dos meios-dias de novembro. Esta melancolia era um plágio ao detestável pavor monacal de outra casa de educação, o negro Caraça de Minas (...). No dia da festa da educação física, como rezava o programa (...) não percebi a sensação de ermo tão acentuada em sítios montanhosos, que havia de notar depois. As galas do momento faziam sorrir a paisagem (Pompeia, 1993, p. 26 - grifos nossos).

Embora pudesse parecer, na concepção do protagonista, "as galas do momento" que "faziam sorrir a paisagem" não serviam planejadamente para velar o que também de perverso permeia as relações escolares (inclusive no Ateneu): as violências físicas, as molestações, os processos vexatórios, etc. As "galas" eram elementos que compunham o imaginário escolar, universo tanto de festas e ostentação de valores louváveis quanto de desavenças e punições.

A presença de um "público, pais e correspondentes em geral (...) mais numeroso do que se esperava" permite observar que os ritos contam com uma adesão pública seleta, fortalecendo a legitimidade dos ritos e sua execução. As solenidades de fim de ano n'O Ateneu contavam com apresentações artísticas, laureação dos melhores alunos, discursos acerca da educação e da política, e com figuras da corte imperial como espectadores. Assim, essas apresentações eram aplaudidas por um público que razoavelmente compartilhava do mesmo habitus dos seus protagonistas (os alunos), o que conferia adesão imediata às mesmas. Neste aspecto, atuando 
como instrumentos de diferenciação, os ritos que envolviam as laureações conferiam títulos de distinção, marcas, classificações - ou, numa palavra: identidades. Essas tendiam a inscrever nos agentes o "dever-ser" que implica condutas que os ritos prescrevem (Bourdieu, 1982). A laureação dos alunos aparece como mecanismo de produção da distinção e, ao mesmo tempo, do exemplar. Assim, devido à magia que o ritual produz, a laureação mantinha velada a ideia de que os alunos de comportamento e rendimento "exemplar" eram, mais precisamente, exceções em um determinado grupo.

O sistema de ritos do Ateneu garante a suspensão da percepção do arbitrário cultural que o determina. Deste modo, ao reconhecer que os valores que os rituais procuram inculcar são legítimos, estabelece-se um tipo particular de dominação simbólica no interior do colégio. Esta dominação permite que a ordem social se reproduza, naturalizando os valores que a sustentam. Contudo, esta dominação é branda, pois implica um acordo entre as partes envolvidas. A dominação simbólica só pode ser aceita na medida em que coloca em jogo lucros (simbólicos) amplamente reconhecidos, como no caso dos méritos que os rituais escolares destacam.

A realização dos rituais contribui na produção de um habitus. A participação dos alunos, que têm idade média de 11 a 17 anos, permite que a força do costume, do hábito, se estabeleça em suas vidas. Esta força os faz se familiarizarem pouco a pouco com rituais, porventura, também exteriores ao internato. Como integrantes de colégio de elite, os alunos são fortemente inclinados a ocupar cargos de notoriedade pública na vida adulta, a discursar em público, a participar de cerimônias requintadas. Ou seja: a ocupar posições sociais onde os ritos de distinção são comuns. Deste modo, exigese que correspondam às expectativas sociais referentes à formação que obtiveram no seio de um grupo prestigioso, neste caso, no colégio Ateneu. Portanto, supõe-se que o processo de familiarização com os rituais, que se inicia no colégio, permite que os alunos, em sua vida social adulta, lidem com eventos da mesma ordem de maneira desembaraçada. A admiração e o encanto do seleto público que assiste aos eventos ginásticos coloca em suspenso (faz esquecer), dessa forma, os investimentos materiais e simbólicos que são as condições mesmas de produção de um ethos masculino socialmente distinto. 
Aristarco, o diretor do Ateneu, é o agente que, concentrando determinado volume de capital social e simbólico, aciona, com sua autoridade, os ritos. Ele é a instituição incorporada e nele personificada:

Diante da arquibancada, ostentava-se uma mesa de grosso pano verde e borlas de ouro. Lá estava o diretor, o ministro do império, a comissão dos prêmios. Eu via e ouvia. Houve uma alocução comovente de Aristarco; houve discursos de alunos e mestres; houve cantos, poesias declamadas em diversas línguas. $\mathrm{O}$ espetáculo comunicava-me certo prazer respeitoso (Pompeia, 1993, p. 25).

A figura majestática de Aristarco expressa o reconhecimento coletivo imanente às práticas rituais:

Nas ocasiões de aparato é que se podia tomar o pulso ao homem. Não só as condecorações gritavam-Ihe do peito como uma couraça de grilos: Ateneu! Ateneu! Aristarco, todo era um anúncio. Os gestos, calmos, soberanos, eram de um rei (...) (Pompeia, 1993, p. 24).

Como parte das relações sociais presentes no Ateneu, a relação de hierarquia permite uma atuação destacada e legitimada de Aristarco nos ritos - atuação que lhe confere lucro simbólico ao ser reconhecido agente das propriedades valiosas que os ritos acionam. Deste modo, a posição hierárquica ocupada por determinados agentes os autorizam a exercer a nomeação que os ritos operam (como é o caso também dos nobres que participavam das solenidades n'O Ateneu):

Deram fim à festa os saltos, os páreos de carreira, as lutas romanas e a distribuição dos prêmios de ginástica, que a mão egrégia da Sereníssima Princesa e a pouco menos do Esposo Augusto alfinetavam sobre os peitos vencedores (Pompeia, 1993, p. 28).

Como já se observou, o processo ritual confere títulos que são publicamente reconhecidos e apreciados. A "distribuição dos prêmios de ginástica" se inscreve elementarmente em um regime meritocrático que recompensa talentos individuais e que não está necessariamente ligado aos ritos. Esses se apropriam do regime meritocrático instalado no Ateneu à medida que consagram seus resultados. A "Sereníssima Princesa" que distribui os prêmios confere marcas que dividem os alunos entre recompensados e não recompensados, sendo que o valor da recompensa está precisamente na raridade dos momentos dessa concessão e na singularidade de quem (agente ou instituição) a concede. Enquanto personagem singularmente ilustre, a Princesa é representante máxima dessa raridade. 
Embora os ritos pareçam atuar sempre de forma harmônica - como uma orquestra que é interrompida apenas quando chega à última nota -, sempre pode haver aquele como Jorge, paradoxalmente filho de Aristarco, que resiste à prática do rito:

Uma coisa o entristeceu [Aristarco], um pequenino escândalo. Seu filho Jorge, na distribuição dos prêmios, recusara-se a beijar a mão da princesa, como faziam todos ao receber a medalha. Era republicano o pirralho! Tinha já aos quinze anos as convicções ossificadas na espinha inflexível do caráter! (Pompeia, 1993, p. 29).

Jorge é uma forma de apóstota, o que renuncia à crença que lhe está predestinada. Renegar uma parte da sequência que compõe o rito é uma forma de profaná-lo em sua totalidade. Neste sentido, é como se Jorge cuspisse a hóstia em meio à celebração religiosa. Deste modo, ele fica sujeito às coerções que procuram restabelecer a ordem simbólica não somente do rito, mas da ordem (ameaçada) no próprio colégio. São práticas de resistência que exprimem uma relativa fragilidade da autoridade:

Aristarco, porém, chamou o menino à parte. Encarou-o silenciosamente e nada mais. E ninguém mais viu o republicano! Consumira-se naturalmente 0 infeliz, cremado ao fogo daquele olhar! Nesse momento as bandas tocavam o hino da monarquia jurada, última verba do programa (Pompeia, 1993, p. 29).

O sentido lúdico ou festivo do rito que compõe a festa da ginástica se intensifica na medida que conta com a exibição da atividade ginástica reconhecida, a priori, como jogo. $\mathrm{O}$ jogo "se processa dentro de certos limites temporais e espaciais, segundo uma determinada ordem e um dado número de regras livremente aceitas, e fora da esfera da necessidade ou da utilidade material" (Huizinga, 2001, p. 147). O sentido lúdico da ginástica recebe, portanto, uma dose maior de magia quando dispõe dos mecanismos consagradores da festa que incita subjetivamente os agentes a participar das (ordinárias) atividades escolares da ginástica, Ihes oferecendo a possibilidade (extraordinária) de compartilhar glórias.

\section{"De fazer febre": o rito dos exames}

Os exames escolares são tão ritualizados quanto as festas de fim de ano, mas, em contraste com essas, afastam o lúdico e a gala, destacando a seriedade, o rigor e o que há de sombrio em uma avaliação escolar. Assim, se 
as galas da festa da ginástica fazem "sorrir a paisagem" da escola, os ritos dos exames são de "fazer febre" aos estudantes, pois um corpo de professores orienta esses ritos por meio de comissões "cada qual mais poderosa e carrancuda" que a outra. Os professores "Courroux da mesa de francês", Simas "da mesa de geografia", Meireles "da filosofia", Barros Andrade "da retórica" são os responsáveis pela tarefa de medir o aprendizado dos alunos em relação ao saber arbitrado no colégio Ateneu. A sua autoridade simbólica garante a condição de produção (com a adesão dos avaliados) de juízos que variam da "reprovação" até a "aprovação com louvor". Os juízos são dotados de uma força de convencimento que orienta todo o corpo do colégio a aderir ao ponto de vista que se impõe como legítimo. Esse ponto de vista dominante estabelece princípios que distinguem a boa da má nota produzida nos exames.

Os exames, considerados por Sérgio como "o terror acadêmico!", são marcados por sucessivas práticas que, mais tarde, com a divulgação das notas obtidas, (re)definem o estado ou posição dos agentes. Estes exames ocorrem em determinados dias e por meio de rotinas próprias, configurando, assim, emoções específicas, muito diferentes, como se viu, daquelas das festas de fim de ano:

A estreia do primeiro exame foi de fazer febre. Três dias antes pulavam-me as palpitações; o apetite desapareceu; o sono depois do apetite; na manhã do ato, as noções mais elementares da matéria com o apetite e com o sono. Memória in albis (Pompeia, 1993, p. 167).

Se a apreensão causada pelos exames chega a "fazer febre" no agente é porque este os compreende como práticas que definem e apontam destinos. E cuja incerteza só acaba com a divulgação das notas. A confiança nos vereditos dos exames escolares de alguma forma se manifesta, portanto, através da crença na capacidade do rito imprimir o caminho a ser seguido. Se o rito dos exames se apresenta por vezes como algo intransponível para alguns agentes, como no caso de Sérgio, é porque está, a todo momento, interrogando objetiva e subjetivamente a capacidade daquele que a ele se submete. Afinal, reconhecer-se capaz de cumprir as exigências previstas no rito significa incorporar aquilo que os ritos autorizam ser, cumprindo um conjunto de expectativas sociais. Neste sentido, os ritos conferem mais do que um caminho a ser seguido: eles prescrevem o que o agente deve ser. 
Uma das etapas implícitas no rito dos exames é a da convocação, cujo tempo de espera é o tempo da indefinição. Um tempo em suspenso e cujo 'suspense' anuncia o drama de uma condenação: as emoções que cercam a convocação são a sensação de "quase morte" para os estudantes que a aguardam. $\mathrm{O}$ rito individualiza e, portanto, a convocação é feita por meio de nomes que são tomados como essências pré-existentes (derivadas do rito de batismo), reatualizando as individualidades por meio dos resultados obtidos:

Ali estive não sei que tempo, como um condenado em oratório. Em redor de mim, morriam de palidez outros infelizes, esperando a chamada. (...) De repente abre-se uma porta. De dentro, do escuro, saía uma voz, uma lista de nomes: um, outro, outro... ainda não era o meu... Afinal! Não houve nem tempo para um desmaio. Empurraram-me; a porta fechou-se; sem consciência dos passos, achei-me numa sala grande, silente, sombria, de teto baixo, de vigas pintadas, que fazia dobrar-se a cabeça instintivamente (Pompeia, 1993, p. 167).

O sentido dramático que Sérgio atribui aos processos do exame pode ser compreendido na medida em que sua experiência escolar é tomada como uma aventura mais ou menos épica. Contando que provações, desafios, riscos, conquistas e derrotas fazem parte da vida escolar, os ritos transferem a essa rotina dimensões épicas porque destacam os elementos que a compõem. Os ritos fazem crer que a vida é uma aventura que se estabelece em meio a travessias nas quais aqueles representam não apenas a consagração do ponto de chegada, mas também um novo ponto de partida. Essa nova partida contempla horizontes relativamente previsíveis a serem perseguidos pelos agentes que levam em conta o sentido de destino que os ritos tendem a thes conferir. Desta forma, os ritos propõem sentido à vida escolar nos dois sentidos da palavra: atribuindo significado e direção a ela.

O cenário das provações pelo qual é preciso passar nos exames escolares n'O Ateneu pode ser representado pela ilustração feita pelo próprio autor do romance (Pompeia, 1993, p. 165): 
Figura 1 - A mesa dos examinadores

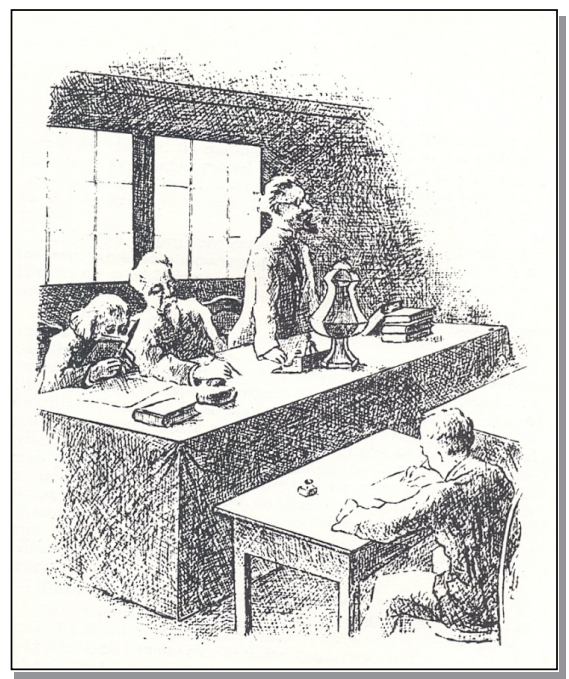

\section{O livro das notas - "a mais terrível das instituições do Ateneu" e o "contágio da convicção"}

Como espaço educativo que procura inculcar disposições físicas e intelectuais, o Ateneu também estabelece ritos acerca da divulgação do aprendizado escolar. O "livro das notas" (que as torna públicas) tem "capa de couro" e é lido, "infalivelmente, perante o colégio em peso", "todas as manhãs", "às oito horas". Tornado legítimo e distinto por uma série de condições simbólicas, o livro das notas confere distinção entre agentes que, a princípio, ocupam uma mesma posição (a de alunos). Deste modo, o livro se inscreve como rito de instituição de diferenças, bem como de identidades, uma vez que os alunos são, através dele, alvo de classificações positivas ou negativas que transformam ou preservam suas posições ou status por meio da atribuição das notas. Assim, este rito cumpre funções ambíguas: a de valorizar ou a de estigmatizar aqueles submetidos ao seu juízo.

Os ritos, portanto, nem sempre têm a função de consagrar prestígio como o atribuído na festa da ginástica. Eles podem também estar explicitamente orientados para produzir estigmas, isto é, marcas que desvalorizam publicamente o agente: 
A mais terrível das instituições do Ateneu não era a famosa justiça do arbítrio, não era ainda a cafua, asilo das trevas e do soluço, sanção das culpas enormes. Era o Livro das notas. Todas as manhãs, infalivelmente, perante o colégio em peso, congregado para o primeiro almoço, às oito horas, o diretor aparecia a uma porta, com a solenidade tarda das aparições, e abria o memorial das partes. Um livro de lembranças comprido e grosso, capa de couro, rótulo vermelho na capa, ângulos do mesmo sangue (Pompeia, 1993, p. $67)$.

O ritual da leitura do livro das notas permite observar a relação entre os ritos dos exames e os da divulgação de seus resultados. O livro é depositário do arquivo produzido por intermédio dos exames. Ele armazena não apenas nomes e notas dos alunos, mas também o histórico de provações no interior do colégio experimentado por cada aluno. Este histórico permite a verificação do desenvolvimento de cada um com relação ao grau das competências curriculares esperadas no Ateneu. E permite, além dessa verificação individual, comparar alunos, inserindo-os em uma rede hierárquica decorrente do veredicto de "bom" ou "mau aluno" arbitrado pela atribuição das notas.

Receber a divulgação das notas "todas as manhãs", no mesmo instante do "primeiro almoço", pode ter o sentido de ser o primeiro alimento do dia. Compondo a mesa do café da manhã, os resultados divulgados pelo livro se inscrevem no roteiro da digestão matinal. De modo que as notas são a 'impressão' do colégio a respeito dos alunos, elas os fazem conhecer a "opinião do Ateneu" como força coercitiva, para o bom ou o mau resultado. 0 que da leitura resulta é a instituição de uma verdade tão objetiva quanto o podem ser os números que exprimem as notas. Desta forma, uma marca, um estigma, uma diferença se impõe diariamente aos alunos, procurando tornálos cientes (e, com isso, responsabilizá-los) de sua atuação no colégio. Se as notas fossem lidas à noite, contando com o intervalo do sono, a marca que elas conferem poderia ser razoavelmente esquecida. No entanto, a leitura das notas pela manhã suspende esta possibilidade porque ela perdura por todo o dia como sentença que circunscreve cada um.

A ilustração seguinte representa o momento da leitura das notas (Pompeia, 1993, p. 65): 
Figura 2 - A leitura do "livro das notas"

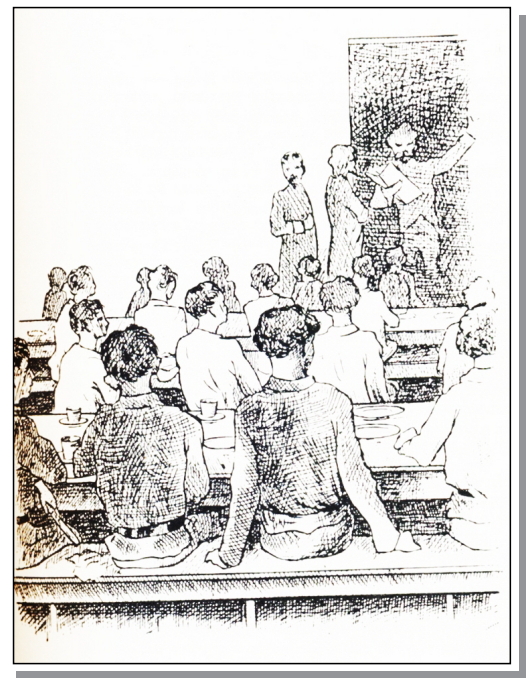

A força que exerce a divulgação das notas reside também na posição do agente divulgador, que se define em relação às outras posições. Quem divulga as notas ocupa a posição de Diretor. No entanto, o poder de convencimento das palavras do diretor reside não nelas mesmas e sim na especificidade da relação entre agentes que se concebem como emissores e receptores de palavras consideradas legítimas:

E pior é que lavrava o contágio da convicção e surpreendia-se cada um consecutivamente de não haver reparado que era mesmo tão ordinário tal discípulo, tal colega, reforçando-se passivamente o conceito, até consumar-se a obra de vilipêndio quando, por último, o condenado, sem mais uma sugestão de revolta, achava aquilo justo e baixava a cabeça. A opinião é um adversário infernal que conta com a cumplicidade, enfim, da própria vítima (Pompeia, 1993, p. 68).

É confiando, portanto, na emissão de um juízo capaz de definir realidades e identidades que ele pode ser tomado como instrumento de 'revelação' do real ou como verdade. Deste modo, o livro das notas surte o efeito de "revelar a verdade" a cada consciência, o que lhe estava até então velado. A cada um cabe a tarefa desse autoconvencimento, da aceitação de um fato que, se antes não estava claro, é porque ainda não havia sido 
percebido como verdade. O livro das notas é que a revela, ao mesmo tempo, a todos. Assim, o que o protagonista chama ironicamente de "contágio da convicção" pode ser entendido como metáfora de moléstia que se alastra pelo contato (contaminação), ou o que os antropólogos sociais hoje consideram como parte do processo de estigmatização social: a crença que marca indelevelmente aqueles a que ela se refere. Deste modo, "a opinião", "que conta com a cumplicidade, enfim, da própria vítima", se inscreve em uma rede de reconhecimentos que faz dos alunos efetivamente cúmplices dessa "opinião" (os resultados dos exames) que lhes é ao mesmo tempo alheia e própria, pois tornados responsáveis por sua enunciação. Esta crença suspende a impressão do arbitrário que determina a opinião (ou julgamento) do Ateneu, ocultando-o sob o véu "natural" do regime escolar:

À medida que se desenrolava a gazetilha, as ânsias iam serenando. Os vitimados fugiam, acabrunhados de vergonha, oprimidos sob o castigo incalculável de trezentas carinhas de ironia superior ou compaixão de ultraje. Passavam junto de Aristarco ao sair para a tarefa penal de escrita (Pompeia, 1993, p. 68).

Ao ritualizar a emissão de um juízo e a atribuição de uma marca depreciada ou estigma (morte simbólica), o rito permite que sobre essa se atue no sentido de corrigi-la. No regime escolar tradicional, essa correção passa pela punição escrita ou pela "tarefa penal de escrita". Essa punição, ao mesmo tempo em que procura reabilitar os agentes à normalidade da conduta escolar, os torna conscientes de suas falhas e de seu estado desviante ou anormal. Somente o ritual seguinte de divulgação das novas notas poderá retirar (relativamente) ou confirmar a permanência do estigma. É por essa razão que o ritual do livro das notas se repete a cada dia, pois a divulgação do resultado de uma nota positiva pode ser uma forma tácita de redenção (renascimento simbólico).

No entanto, a trajetória escolar de Sérgio revela não um processo de redenção, mas a degradação progressiva de sua condição, diariamente reafirmada pela divulgação das notas:

No dia seguinte ao almoço, amargava eu, sem açúcar que me bastasse, o resto do café quinado da expectativa (porque Mânlio tinha-me prevenido), quando ouvi Aristarco, alargando pausas dramáticas de comoção, ler, claro, severo: "O Sr. Sérgio tem degenerado..." (...). Dias depois da terrível nota, voltava eu a figurar com outra má, menos filosoficamente redigida, porém agravada de reincidência. Aristarco não perdoou mais. Houve ainda terceira, quarta, por diante (Pompeia, 1993, p. 69). 


\section{Considerações finais}

Se os ritos de instituição compõem a rotina escolar é porque eles cumprem funções não apenas objetivas como as de dividir e diferenciar os agentes por meio da distribuição de títulos de distinção ou estigma. Os ritos também cumprem a função subjetiva de atribuir sentido à vida escolar. É nessa perspectiva que funcionam como "mecanismos de incentivo" ao trabalho realizado na escola, no sentido apontado por Saviani (2008, p. 52). Forma de vida institucionalizada, a escola só pode ser considerada admissível enquanto oferece razões convincentes para ser aceita e vivida pelos agentes. É por isso que os ritos de instituição escolares também reconhecem o fato da vida não ser algo que se encerra na escola. Ela age como meio de formação que propicia a passagem para outro meio e posição social. Os ritos tendem, assim, a produzir nos agentes que os sofreram a capacidade de deslumbrar novos horizontes enquanto promessas daquilo que o rito enuncia explícita e implicitamente.

O rito também produz sensações corpóreas, isto é, que se manifestam visualmente no agente na forma de ansiedade, nervosismo, medo, insegurança, etc. Estes sentimentos podem ser compreendidos como efeitos da própria crença que é depositada no rito, isto é, naquilo que o rito anuncia (a mudança de status). A margem de tempo que antecede o rito é o tempo, portanto, da incerteza, da indecisão entre aquilo que se é e aquilo que se poderia ser. É o tempo da margem ou da liminaridade social. Momento suspenso no tempo porque suspende as identidades, quando ainda não se é uma coisa nem outra.

Os sentimentos que acompanham a execução dos ritos ganham sua forma mais dramática pela possibilidade do agente ser capaz de prever uma "pequena morte". O veredito formulado a partir dos exames e da divulgação das notas faz lembrar que a vida escolar pode ser continuamente descontínua, isto é, uma vida sujeita a interrupções devido às provações que ela demanda. Trata-se de uma morte "pequena" porque é simbólica, momentânea e não se realiza completamente. O próprio circuito de ritos do Ateneu oferece os meios de superar essa "morte" à medida que incita o agente a se nutrir de novas expectativas. Viver a possibilidade da "pequena morte" significa, portanto, experimentar o espaço escolar como espaço onde se corre os "riscos do jogo". 
Os ritos permitem regular uma forma específica de illusio, isto é, uma forma "de reconhecer o jogo e reconhecer o que está em disputa no jogo" (Bourdieu, 1994, p. 151). Tanto nas consagrações quanto nas estigmatizações executadas nos ritos são enunciados implicitamente os princípios que orientam o jogo escolar do Ateneu. O rito confirma desde cedo que existem regras, condutas que devem ser preservadas ou transformadas. Mantendo um circuito de ritos, o Ateneu incita constantemente os agentes a não apenas participar do jogo, mas também a desenvolver o fair-play. Em suma, os ritos fazem lembrar que não pode haver outro sentido em participar das atividades do Ateneu além dos sentidos que previamente se concentram naqueles ritos. Podemos considerar os ritos, portanto, como uma forma de regulação da libido scholasticus no Ateneu. Os ritos confirmam a validade dos desejos construídos no interior do colégio: o desejo de ser um bom ginasta, de ser bom aluno, etc.

Sobre este pano de fundo, as práticas que compõem os ritos no Ateneu são valorizadas enquanto suprassumo da educação da época. Ou seja, a crença que torna legítima a prática dos rituais não se apoia fundamentalmente neles mesmos, mas advém da compreensão da educação em sentido mais amplo. Cabe, assim, ao rito, a função de ratificar e reproduzir a crença atribuída à escola, consagrando-a.

\section{Notas}

1 Embora não excludentes, consideram-se duas possibilidades de investigação do romance como obra cultural - a sua leitura externa (a partir da autoria e estrutura do campo literário/artístico em que a obra foi produzida) e a leitura interna (a partir da estrutura da obra ou de seus 'dados sensíveis'). Assim, embora estudos indiquem que $O$ Ateneu contém elementos autobiográficos resultantes das experiências que o autor, Raul Pompeia, vivenciou como aluno interno no colégio Abílio Cesar Borges (cf. Andrade, 1972; Miguel-Pereira, 1973; Veríssimo, 1979; Moisés, 1983; Bosi, 1988; Gondra, 1999), aqui optamos por realizar apenas a leitura interna da obra. Nesse sentido, nos absteremos de considerar O Ateneu como romance autobiográfico, apenas nos interessando por aquilo que ele enuncia da vida escolar da época retratada no romance.

2 Este artigo é derivado de dissertação de Mestrado em Educação (com financiamento da bolsa de demanda social da CAPES) intitulada "O Ateneu: uma análise sociológica dos mecanismos disciplinares no romance de Raul Pompeia", de autoria de Tiago Ribeiro Santos, sob orientação da prof. Dra. Rita de Cássia Marchi, defendida na Universidade Regional de Blumenau (PPGE/FURB). O texto 
deste artigo é inédito em relação ao da dissertação e também em relação ao artigo "O disciplinamento do espírito: uma análise dos ritos de instituição no romance $\mathrm{O}$ Ateneu" apresentado no IX Seminário de Pesquisa em Educação da Região Sul (ANPEDSUL, 2012). No presente artigo suspendemos a dimensão disciplinar dos ritos no espaço escolar, passando a enfocá-los, de modo mais geral, como instituidores do sentido e da crença escolar.

3 Rodolpho (2004) menciona Rivière (1997), que analisa os ritos profanos que vivenciamos em nosso cotidiano e a que somos submetidos desde muito pequenos, como o caso dos ritos praticados na escola. Para esse autor, a exemplo do que é visto nessa introdução, os ritos atribuem a cada um de nós novas identidades e novos papéis a serem desempenhados junto ao(s) grupo(s) nos quais vivemos, sendo a escola um dentre eles.

\section{Referências}

Andrade, M. (1972). Aspectos da literatura brasileira. São Paulo: Martins.

Bosi, A. (1988). Céu, inferno. São Paulo: Ática

Bourdieu, P. (1982). Les rites comme actes d'institution. Actes de la recherche en sciences sociales, 43, 58-63.

Bourdieu, P. (1994). Raisons pratiques: Sur la théorie de l'action. Paris: Éditions du Seil.

Bourdieu, P. (1996). As regras da arte: Gênese e estrutura do campo literário. São Paulo: Companhia das Letras.

Bourdieu, P., \& Chartier, R. (2011). O sociólogo e o historiador. Belo Horizonte: Autêntica.

Gondra, J. (1999). Arquivamento da vida escolar: Um estudo sobre O Atheneu. In D. G. Vidal \& M. C. C. Souza (Orgs.), A memória e a sombra: A escola brasileira entre o império e a república. Belo Horizonte: Autêntica.

Gondra, J. (2004). O corpo educado. In J. Gondra, Artes de civilizar: Medicina, higiene e educação na corte imperial. Rio de Janeiro: Ed. UERJ.

Huizinga, J. (2001). Homo ludens: O jogo como elemento da cultura. São Paulo: Perspectiva.

Miguel-Pereira, L. (1973). História da literatura brasileira. Rio de Janeiro: José Olympio.

Moisés, M. (1983). História da literatura brasileira. São Paulo: Cultrix.

Pompeia, R. (1993). O Ateneu: Apuração do texto em confronto com o original e introdução por Therezinha Bartholo. Rio de Janeiro: Francisco Alves.

Rodolpho, A. L. (2004). Rituais, ritos de passagem e de iniciação: Uma revisão da bibliografia antropológica. Estudos Teológicos, 44, 138-146.

Saviani, D. (2008). História das idéias pedagógicas no Brasil. Campinas: Autores Associados.

Turner, V. W. (1974). O processo ritual: Estrutura e anti-estrutura. Petrópolis: Vozes.

Vangennep, A. (1978). Os ritos de passagem. Petrópolis: Vozes.

Veríssimo, J. (1979). Últimos estudos de literatura brasileira. Belo Horizonte: Itatiaia. 
THE SPREAD OF SCHOOL BELIEF OR THE "TRANSMISSION OF CONVICTION": THE RITES OF INSTITUTION IN O ATENEU

\section{Abstract}

This article, in the interface of sociology of education with history of education, presents an analysis of the rites of institution described in the novel OAteneu, authored by the Brazilian writer Raul Pompeia and originally published in 1888. The novel portrays the daily life of a wealthy school of the time. The rites of institution in Ateneu school act to produce - reproducing - the belief in school life, establishing differences among the targeted individuals. In this sense, ritual acts to convince the school agents of supporting and taking part in various activities of the school, collectively orchestrating the different interests, dispositions and modes of conduct.

Keywords

Rites of institution; School life; Novel

\section{LA PROPAGATION DE LA CROYANCE SCOLAIRE ET LA "CONTAGION DE LA CONVICTION": LES RITES D'INSTITUTION DANS O ATENEU}

Résumé

Cet article, dans l'interface de la sociologie de l'éducation et de l'histoire de l'éducation, présente une analyse des rites d'institution décrits dans le roman O Ateneu, de l'écrivain brésilien Raul Pompeia, paru pour la première fois en 1888. Le roman rapporte le quotidien d'un collège de l'élite de l'époque. Les rites d'institution au collège Ateneu exercent une action dans le sens de produire - en reproduisant - la croyance dans la vie scolaire, en établissant des différences entre les individus à qui ils sont destinés. Dans ce sens, les rites scolaires agissent pour convaincre les agents à l'adhésion et à la 
participation aux différentes activités du collège, en orchestrant d'une façon collective les divers intérêts, dispositions et modes de conduite.

Mots-clé

Rites d'institution; Vie scolaire; Roman

Recebido em Junho/2012 Aceite para publicação em Maio/2013 